\title{
Effect of VBC-1814/7J, a poly-phytocompound, on a non-infectious model of pharyngitis
}

\author{
JUNJI UEMURA ${ }^{1}$, RAVINDER NAGPAL $^{2}$, NICOLA ZERBINATI ${ }^{3}$, BIRBAL SINGH $^{4}$, \\ MASSIMILIANO MARCELLINO ${ }^{5}$, DHEERAJ MOHANIA ${ }^{6}$, FRANCESCO MAROTTA ${ }^{5}$, FANG HE ${ }^{7}$, \\ ANTONIO AYALA $^{8}$, YASUHIRO KASUGAI ${ }^{1}$ and ROBERTO CATANZARO ${ }^{9}$
}

\begin{abstract}
${ }^{1}$ Suheiro Chem-Tech Center, Niigata 950-1447; ${ }^{2}$ Division of Laboratories for Probiotic Research, Juntendo University Graduate School of Medicine, Tokyo 162-0803, Japan; ${ }^{3}$ CMP-Medical Center and Laboratories, I-27100 Pavia, Italy;

${ }^{4}$ Indian Veterinary Research Institute, Regional Station, Palampur, Himachal Pradesh 176061, India;

${ }^{5}$ ReGenera Research Group for Aging Intervention, I-20154 Milan, Italy; ${ }^{6}$ Animal Biochemistry Division, National Dairy Research Institute, Karnal, Haryana 121001, India; ${ }^{7}$ Department of Nutrition and Food Hygiene, West China School of Public Health, Sichuan University, Chengdu, Sichuan 610000, P.R. China; ${ }^{8}$ Department of Biochemistry and Molecular Biology, Seville University, I-41000 Seville, Spain;

${ }^{9}$ Department of Internal Medicine, University of Catania, 95121 Catania, Italy
\end{abstract}

Received November 3, 2014; Accepted January 13, 2015

DOI: $10.3892 /$ etm.2017.4332

\begin{abstract}
Pharyngitis presents as an inflammation of the oropharynx, and clinical examination often shows evidence of nasopharyngitis. In numerous cases the condition occurs as a self-limiting illness of non-infectious aetiology, whose clinical management remains a matter for debate given the inappropriateness of antibiotics, the reported worsening following steroid use and the recent discouragement of the use of Chinese herbal medicine. The aim of the present study was thus to test VBC-1814/7J, a poly-phytocompound with known anti-inflammatory and immune-response enhancing properties, in an experimental model of non-infectious pharyngitis. Experimental non-infectious pharyngitis was induced by applying a pyridine solution to the surface of the pharyngeal mucosa in rats that were either normally fed (group A) or fed VBC-1814/7J three days prior to and three days subsequent to the induction of pharyngitis (group B). Healthy rats treated with topical saline were used as a control (group C). At time-points of 0 , one hour, one day and three days sacrifices were carried out and microscopic examination, Evans blue (EB) dye extravasation and tissue concentrations of tumour necrosis factor (TNF)- $\alpha$, interleukin (IL)- 6 and mRNA of $\alpha$ - and $\beta$-defensins were studied. As compared with group $\mathrm{C}$, group A showed significant microscopic damage, EB
\end{abstract}

Correspondence to: Professor Francesco Marotta, ReGenera Research Group for Aging Intervention, 12 Piazza Firenze, I-20154 Milan, Italy

E-mail: fmarchimede@libero.it

Key words: non-infectious model of pharyngitis, phytocompound, $\beta$-defensins extravasation, and increases in the levels of TNF- $\alpha$ and IL-6, as well as in the mRNA of three defensins $(\mathrm{P}<0.001)$ on the third day of observation. VBC-1814/7J significantly mitigated these microscopic and inflammatory markers while allowing a prompter and wider defensin reaction $(\mathrm{P}<0.05$ vs. group $\mathrm{A})$. These data suggest that VBC-1814/7J, as demonstrated in earlier studies, has the potential to address non-infectious pharyngitis in clinical practice.

\section{Introduction}

Pharyngitis, commonly referred to as a sore throat, represents an inflammation of the oropharynx, with clinical examination often showing evidence of nasopharyngitis. Patients most often report irritation and painful discomfort, either when swallowing saliva or at rest, which may be objectivised through the observation of inflammation in the medium and lower part of the pharynx. In certain cases the condition is associated with a non-infectious aetiology and, in such a setting, antibiotics may be the wrong choice or they may just offer a modest improvement (1). In the majority of individuals with a sore throat the clinical course is self-limiting, although the symptoms may vary in duration and cause significant discomfort. Among the causes of non-infectious pharyngitis are active and passive smoking; excessive use of the voice or improper voice modulation; air pollution, including indoor pollution (sick building syndrome); a number of occupational exposures to fumes and volatile agents or, in certain asthmatic patients, the use of inhaled steroids (2-12).

Given the wide range of, often obscure, aetiologies, the rather vague boundaries of its nosologic assessment and the paucity of stringent inclusion criteria in most studies, which are often biased by considering acute or chronic pharyngitis at the same time, the clinical management of non-infectious sore throat remains a matter for discussion. This debatable clinical management of pharyngitis may also explain the 
wide self-prescription of over-the-counter remedies with analgesic and claimed anti-inflammatory compounds.

In extensive reviews tackling the issue of 24- to 48-h outcomes in the treatment of non-infectious sore throats, steroids, paracetamol and, most significantly, non-steroidal anti-inflammatory drugs, such as flurbiprofen and nimesulide, have been found to be of some effectiveness (12-14). By contrast, the use of Chinese herbal medicine remains controversial, as the composition of these medicines is often poorly understood, and has been discouraged by a large-scale Cochrane review (15).

We have recently shown that a natural-based compound, VBC-1814/7J (250 mg North American ginseng, $150 \mathrm{mg}$ elderberry, $200 \mathrm{mg}$ vitamin $\mathrm{C}, 11 \mathrm{mg}$ zinc, $100 \mathrm{mg} \beta$-glucan; InfluNam ${ }^{\mathrm{TM}}$, Named S.p.A., Lesmo, Italy), can produce a significant decrease in inflammatory chemokines and viral load in bronchial lavage and in lung tissue in an experimental influenza model (16). This compound is already in use as an over-the-counter remedy due to its known antiviral, antioxidant and antibacterial properties: Elderberry is rich in phenolic compounds, including phenolic acid, flavonoids, catechins and proanthocyanidins, which have been reported to enhance the immune response. Cyanidin-3-glucoside and cyanidin-3-sambubioside have been identified as the main anthocyanins in elderberry $(17,18)$.

Human $\beta$-defensins, a cationic antimicrobial peptide family, are primarily induced in epithelial cells in response to inflammatory stimuli and they play an important role in host defence. $\beta$-defensins are small cysteine-rich proteins that are produced by a number of epithelial and bone-marrow-derived cells and represent a large group of antimicrobial peptides with broad-spectrum activity targeting gram-negative and -positive bacteria, viruses and fungi $(19,20)$. Furthermore, levels of human $\beta$-defensins, together with immunoglobulins $A$ and $G$, have been found to be decreased in infants with recurrent pneumonia. This may be one of the immunity-related reasons for recurrent pneumonia in infants (21), thus highlighting the requirement for proper care of non-infectious pharyngitis.

The aim of the present study was, therefore, to test the above-mentioned poly-phytocompound in an experimental model of non-infectious pharyngitis while focussing on inflammatory markers and defensin production. When considering a non-infectious pharyngitis model, the capsaicin-induced model is widely used since capsaicin is known to bring about the activation of primary afferent sensory neurones and the release of neuropeptides, such as substance $\mathrm{P}$ and neurokinin A, from nerve endings (22). These neuropeptides possess strong proinflammatory effects in the airway tissues, leading to increased vascular permeability and plasma extravasation (23). Given its characteristics, the capsaicin-induced model may not, however, entirely mimic the human condition and the spectrum of possible interventions; thus the pyridine-induced pharyngitis model, which has recently been shown to be a simple and versatile novel animal model for screening drugs against non-infectious pharyngitis in rats, was selected (24).

\section{Materials and methods}

Study protocol. This study was conducted in agreement with the policy and procedures of approved protocols and in accordance with the recommendations for the proper care and use of laboratory animals as detailed in the Guide for the Care and Handling of Laboratory Animals (National Institutes of Health Publication, no. 86-23, 1985). The present study was approved by the Local Ethics Committee of Niigata Prefecture, Japan (permit number HY254/2014).

Animal care. Seventy-five male Wistar rats (Charles River Laboratories, Yokohama, Japan), weighing 280-490 g, were used throughout the experiments. The animals were allowed to adapt to the laboratory environment for one week before beginning the experiment. The rats were housed in independent ventilated cages with free access to tap water; they received pathogen-free food and were maintained in a room under standard conditions of feeding and temperature $\left(26 \pm 1^{\circ} \mathrm{C}\right)$ with a 12-h light/dark cycle.

The animals were anaesthetised with urethane $(2 \mathrm{~g} / \mathrm{kg}$, intraperitoneally; Nippon Shinyaku Co., Ltd., Kyoto, Japan) and placed in the supine position. Spontaneous respiration was maintained via a tracheal cannula following intraperitoneal treatment with atropine sulphate $(0.2 \mathrm{mg} / \mathrm{kg}$; ShenYuan ChemPharm Co., Ltd., Xiaogan, China).

Model of non-infectious pharyngitis and study design. Experimental non-infectious pharyngitis was induced by applying a pyridine solution to the surface of the pharyngeal mucosa which, previously, had been washed twice with $0.5 \mathrm{ml}$ saline. Briefly, the tongue was slightly pulled out and the pharynx area was opened deep into the oral cavity with a small rib spreader, and $50 \mu 13 \%$ pyridine solution was carefully applied with a sterile cotton swab for $5 \mathrm{sec}$ at each time-point, three times. For the control group (15 rats in total), a vehicle (saline) was applied.

Following acclimation the animals were allocated into three groups of 30 animals each for groups A and B and 15 for group C and treated as follows: Group A, the pharyngitis group was treated with a topical application of simple saline; group B, a second pharyngitis group, was treated with $15 \mathrm{mg}$ VBC-1814/7J divided into two daily doses for three days preceding the exposure to the non-infectious pharyngitis model and three days afterwards; group C, the healthy control group, was administered saline to the pharynx as a sham insult.

Evans blue (EB) dye extravasation. EB dye present in the tissue was extracted using $1 \mathrm{ml}$ formamide (Nippon Shinyaku Co., Ltd.). The absorbance of the sample was recorded using a standard plate reader (Synergy ${ }^{\mathrm{TM}}$ HT; BioTek, Winooski, VT, USA) at excitation and emission wavelengths of 620 and $680 \mathrm{~nm}$, respectively. These values were quantified using the standard curve for EB dye where the maximum and minimum detectable concentrations were determined by a Tukey's multiple comparisons test and are indicated by a significant difference in the spectroscopic readings between each incremental increase in concentration (25). Values are expressed in $\mu \mathrm{g} / \mathrm{mg}$ tissue.

Macro-/microscopic assessment. For a quantitative evaluation of the pyridine-induced plasma exudation in the rat pharyngeal mucosa, the extravasation of EB dye into the pharyngeal tissue was assessed. EB dye (30 mg/ $\mathrm{kg}$, intravenous) was 
injected into the femoral vein $10 \mathrm{~min}$ prior to the application of pyridine, and then one hour, one day and three days after pyridine/vehicle application, when 10 animals in each group were sacrificed by deep isoflurane anaesthesia. The head portion was perfused with $180 \mathrm{ml}$ citric acid buffer $(5 \%$ paraformaldehyde in $0.05 \mathrm{M}$ sodium citrate solution adjusted to $\mathrm{pH} 3.5$ with $0.05 \mathrm{M}$ citric acid solution) at a rate of $15 \mathrm{ml} / \mathrm{min}$ to flush out the intravascular EB dye. Both masseter muscles were subsequently incised and the lower jaw was removed to cut the pharynx block out. Macro- and microscopic examination was then carried out, the latter in a blinded fashion, by an experienced pathologist using an optical image analyser (DP72; Olympus Corporation, Tokyo, Japan). The main parameters checked (oedema, glandular hypertrophy, glandular ruptures and haemorrhage spots, and inflammatory infiltrate) were graded as follows: Slight $(+)$, mild to mild/moderate $(++)$, severe $(+++)$ and very severe $(++++)$.

Tissue levels of tumour necrosis factor (TNF)- $\alpha$ and interleukin (IL)-6. A total of $50 \mathrm{mg}$ frozen pharyngeal tissue was gridded in 4-(2-hydroxyethyl)-1-piperazineethanesulfonic acid (HEPES) buffer [20 mM HEPES (pH 7.6), 1.5 mM EDTA, $0.5 \mathrm{mM}$ benzamidine and enzyme inhibitors]. Following centrifugation $\left(36,288 \mathrm{rpm}, 4^{\circ} \mathrm{C}, 20 \mathrm{~min}\right)$, the supernatant was diluted and the TNF- $\alpha$ and IL- 6 levels were quantified according to the manufacturer's instructions using specific ELISA kits (R\&D Systems, Minneapolis, MN, USA). The absorption was read at $450 \mathrm{~nm}$ by a Macrotiter plate reader (Thermo Fisher Scientific Inc., Waltham, MA, USA). Values are expressed in $\mathrm{pg} / \mathrm{ml}$ and normalised to total protein. ELISA procedures were run at room temperature $\left(20-23^{\circ} \mathrm{C}\right)$ and assays were performed in triplicate.

Defensin gene expression: Reverse transcription-quantitative polymerase chain reaction $(R T-q P C R)$ analysis. Under sterile conditions, tissue samples were cut with scissors, rapidly frozen in liquid nitrogen and stored at $-80^{\circ} \mathrm{C}$ until mRNA extraction. The frozen tissue was then finely minced in $1 \mathrm{ml}$ TRIzol ${ }^{\circledR}$ reagent (Invitrogen Life Technologies, Carlsbad, CA, USA) using a Polytron ${ }^{\circledR}$ homogeniser (Jiangsu Makwell Machinery Co., Ltd., Huaian, China). RNA was subsequently isolated using the TRIzol Plus RNA purification system (Invitrogen Life Technologies) and eluted in $50 \mu$ l sterile water, and $3 \mu \mathrm{g}$ total RNA was reverse transcribed using hexamer oligonucleotides in a $20-\mu 1$ reaction volume (Verso cDNA synthesis kit; Thermo Fisher Scientific Inc.). Following dilution to $60 \mu \mathrm{l}$ with sterile water, $2.5 \mu \mathrm{l}$ cDNA served as a template in the RT-qPCR. qPCR analysis was carried out with a Smart Cycler ${ }^{\circledR}$ real-time PCR device with fast SYBR ${ }^{\circledR}$ Green Master Mix (Applied Biosystems; Life Technologies, Foster City, CA, USA). To amplify the defensins tested, 200 ng cDNA was used as a template in a $25-\mu 1$ reaction mixture containing SYBR green RT2-qPCR Master Mix (SABiosciences, Qiagen, Valencia, CA, USA) and a primer mixture. For gene detection, the thermocycling protocol was as follows: $95^{\circ} \mathrm{C}$ for 15 min for polymerase activation, followed by 45 cycles of denaturation at $95^{\circ} \mathrm{C}$ for $30 \mathrm{sec}$, annealing at $60^{\circ} \mathrm{C}$ for $30 \mathrm{sec}$ and extension at $72^{\circ} \mathrm{C}$ for $30 \mathrm{sec}$. SYBR green dye fluorescence was determined at $521 \mathrm{~nm}$ during the annealing phase. The specificity of the PCR products was assessed by melting curve analysis, and amplification products were resolved on a $1.5 \%$ agarose gel to validate the correct sizes of the amplicons. Glyceraldehyde-3-phosphate dehydrogenase (GAPDH) was amplified as a control using 50 ng cDNA as the template. The relative amount of mRNA in each sample was calculated based on its threshold cycle (CT) value in comparison with the CT values of GAPDH.

To detect the levels of $\alpha$-defensins $1,3,4$ and 5 and $\beta$-defensins $1,2,3$ and 4 the following primers were used: $\alpha$-defensin 1 sense, 5'-AGAGCTGCCTGCTCATCCTAA TC-3', antisense, 5'-TCATGCTCGTCTTGTTCTCTGTG-3'; $\alpha$-defensin 3 sense, 5'-TCCTCCTCTCTGCCCTCGT-3', antisense, 5'-GACCCTTTCTGCAGGTCCC-3'; $\alpha$-defensin 4 sense, 5'-ACTTGICCTCCTCTCTGCCCT-3', antisense, 5'-TCGTATTCCACAAGTCCCACG-3'; $\beta$-defensin 1 sense, 5'-TCCTCTCTGCACTCTGGACC-3', antisense, 5'-ATC GCTCGTCCTTTATGTCC-3'; $\beta$-defensin 2 sense, 5'-CCT TTCTACCAGCCATGAGG-3', antisense, 5'-GCAACAGGG GTTCTTCTCTG-3'; $\beta$-defensin 3 sense, 5'-CTCCACCTG CAGCTTTTAGC-3', antisense, 5'-GCTAGGGAGCACTT GTTTGC-3'; $\beta$-defensin 4 sense, 5'-CTCCACTTGCAGCCT TTACC-3', antisense 5'-CATGGAGGAGCAAATCTGG-3' (MultiSciences Biotech Co., Ltd., Hangzhou, China). The results are expressed as changes in gene expression, calculated using the following formula: $\left(\mathrm{CT}_{\text {target gene }}-\mathrm{CT}_{\text {reference gene }}\right.$ of treated rats $) /\left(\mathrm{CT}_{\text {target gene }}-\mathrm{CT}_{\text {reference gene of untreated rats }}\right)$. CT values are expressed in arbitrary units.

Statistical analysis. Statistical analyses were performed using the software package Statistical Analysis Software (SAS) (version 9.3; SAS Institute Inc., Cary, NC, USA). The results are presented as the mean \pm standard error of the mean for each group. Analysis of variance was performed followed by Bonferroni's test. $\mathrm{P}<0.05$ was considered to indicate a statistically significant difference.

\section{Results}

EB dye extravasation and macro- and microscopic observation of the pharynx. Unlike the normal control animals (treated with saline), which exhibited a normal macro- and microscopic structure of the pharynx, the gross inspection of the pharynx in group A (treated with $2.5 \%$ pyridine) showed a moderate bluish colour owing to a significant extravasation phenomenon coupled with inflammatory signs. By contrast, the healthy control rats exhibited a dull blue colour as a sign of negligible or no extravasation of EB dye (data not shown). As expected, pyridine application caused a marked inflammatory oedema and extravasation of EB dye through the pharyngeal mucosa, resulting in an EB tissue concentration that was significantly higher than that in the healthy control group (Fig. 1; $\mathrm{P}<0.001$ ). The histopathological examination revealed the already described changes consisting of submucosal gland hypertrophy, scattered glandular ruptures with haemorrhagic spots, an abundance of mononuclear cells and infiltration of neutrophils (Table I; $\mathrm{P}<0.001$ vs. group $\mathrm{C}$ ). The group treated with VBC-1814/7J showed a less intense blue colour permeation of the mucosa and lower EB and associated EB dye extravasation (Fig. 1; $\mathrm{P}<0.05$ vs. group A). This was further confirmed by the blinded duplicate histological examination revealing a 
Table I. Microscopic observation of the pharynx: Effect of VBC-1814/7J treatment.

\begin{tabular}{|c|c|c|c|c|c|}
\hline Group & Time-point & Oedema & $\begin{array}{c}\text { Gland } \\
\text { hyperthrophy }\end{array}$ & $\begin{array}{l}\text { Gland ruptures/ } \\
\text { haemorrhage }\end{array}$ & $\begin{array}{l}\text { Inflammatory } \\
\text { infiltrate }\end{array}$ \\
\hline \multirow[t]{4}{*}{ A } & 0 & - & - & - & - \\
\hline & $1 \mathrm{~h}$ & $++++^{\mathrm{a}}$ & $+++^{a}$ & $++^{a}$ & $+++{ }^{\mathrm{a}}$ \\
\hline & 1 day & $+++^{\mathrm{a}}$ & $+++^{\mathrm{a}}$ & $+++{ }^{a}$ & $++++{ }^{a}$ \\
\hline & 3 days & ++ & $t^{\mathrm{a}}$ & $++^{a}$ & $+++{ }^{a}$ \\
\hline \multirow[t]{4}{*}{ B } & 0 & - & - & - & - \\
\hline & $1 \mathrm{~h}$ & $++^{\mathrm{b}}$ & $++^{\mathrm{b}}$ & ++ & $++^{\mathrm{b}}$ \\
\hline & 1 day & $++^{\mathrm{b}}$ & $++^{\mathrm{b}}$ & $+^{\mathrm{b}}$ & $++^{\mathrm{b}}$ \\
\hline & 3 days & $+/-^{b}$ & $t^{\mathrm{a}}$ & $+/-^{b}$ & $+^{\mathrm{b}}$ \\
\hline \multirow[t]{4}{*}{$\mathrm{C}$} & 0 & - & - & - & - \\
\hline & $1 \mathrm{~h}$ & - & $+/-$ & - & - \\
\hline & 1 day & - & - & - & - \\
\hline & 3 days & - & - & - & - \\
\hline
\end{tabular}

Evaluation was carried out in a blinded fashion in duplicate by an experienced pathologist supported by a computerised image analyser system. ${ }^{a} \mathrm{P}<0.001$ vs. group $\mathrm{C}$; ${ }^{b} \mathrm{P}<0.05$ vs. group B. Group A, pharyngitis with saline treatment; group B, pharyngitis with $\mathrm{VBC}-1814 / 7 \mathrm{~J}$ treatment; group $\mathrm{C}$, control group; +, slight; ++, mild to mild/moderate; +++, severe; ++++, very severe; +/-, slightly positive.

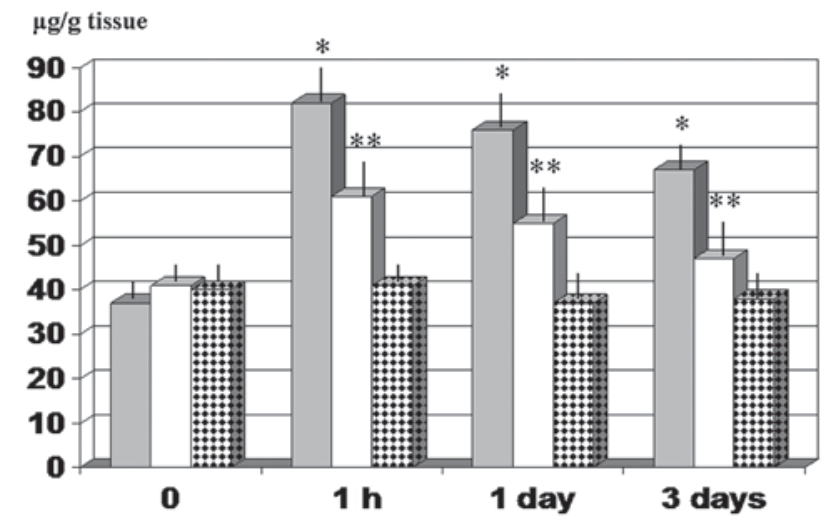

Figure 1. Evans Blue dye extravasation in a pharyngitis model: Effect of VBC-1814/7J. The data are expressed as the mean \pm standard error of the mean. The mean values of the groups were compared with one-way analysis of variance followed by Bonferroni's test. ${ }^{*} \mathrm{P}<0.001$ vs. group $\mathrm{C} ;{ }^{* *} \mathrm{P}<0.05$ vs. group A. Grey bar, untreated pharyngitis group (group A); white bar, phytocompound-treated pharyngitis group (group B); dotted bar, healthy control treated with sham pharyngeal damage (saline).

significant decrease in the main parameters (Table I; $\mathrm{P}<0.05$ vs. group A).

TNF- $\alpha$ and IL-6 concentration in pharyngeal tissue. Tissue levels of TNF- $\alpha$ and IL- 6 in the untreated pharyngitis group (group A) increased rapidly to 3.6- and 1.6-fold that of baseline values, respectively, one hour after pyridine application (Figs. 2 and 3; $\mathrm{P}<0.001$ ). Such an increase was maintained at the one-day time-point but partly declined at the three-day time-point for TNF- $\alpha$. By contrast, the IL-6 concentration reached a peak at the one-day time-point and remained plateaued two days later (Fig. 3). In both cases the cytokine levels were significantly higher throughout the three days of observation as compared with baseline

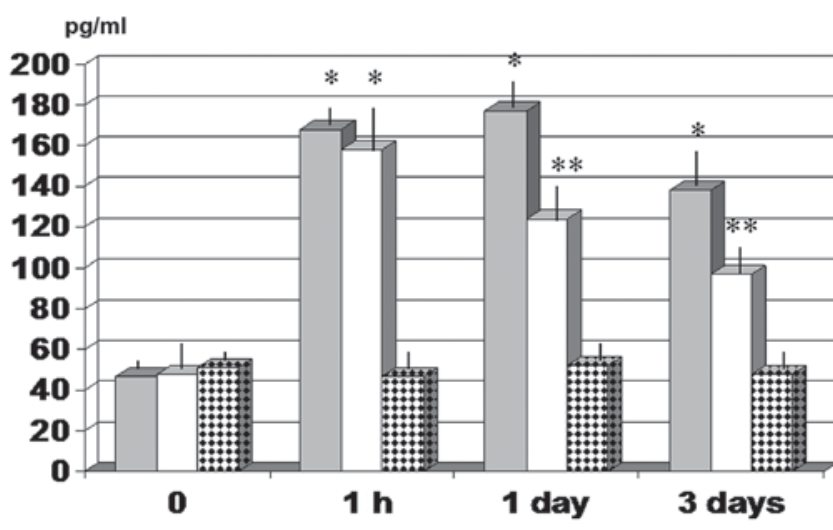

Figure 2. Tumour necrosis factor- $\alpha$ concentration in the pharyngeal tissue of a non-infectious pharyngitis model: Effect of VBC-1814/7J. Values are expressed as the mean \pm standard error of the mean. The mean values of the groups were compared with one-way analysis of variance followed by Bonferroni's test. ${ }^{*} \mathrm{P}<0.001$ vs. group $\mathrm{C} ;{ }^{* *} \mathrm{P}<0.05$ vs. group $\mathrm{A}$. Grey bar, untreated pharyngitis group (group A); white bar, phytocompound-treated pharyngitis group (group B); dotted bar, healthy control treated with sham pharyngeal damage (saline).

values and those in the healthy control group (group C). The VBC-1814/7J-treated group (group B) exhibited a decrease in both parameters, which was substantial at day one of observation and was maintained throughout the study period $(\mathrm{P}<0.05$ vs. group $\mathrm{A})$.

Assessment of defensin mRNA levels in pharyngeal tissue. With the exception of $\beta$-defensins 1,2 and 4 and $\alpha$-defensins 4 and 5, the remaining three defensin mRNA levels out of the eight tested showed a significant increase one hour after induction of pharyngitis as compared with pre-infection values (data not shown; $\mathrm{P}<0.01$ vs. baseline level and group $\mathrm{C}$ ). At the one- and three-day time-points, levels of $\beta$-defensins 1 and 2 mRNA also significantly increased (Fig. 4; $\mathrm{P}<0.001$ vs. 


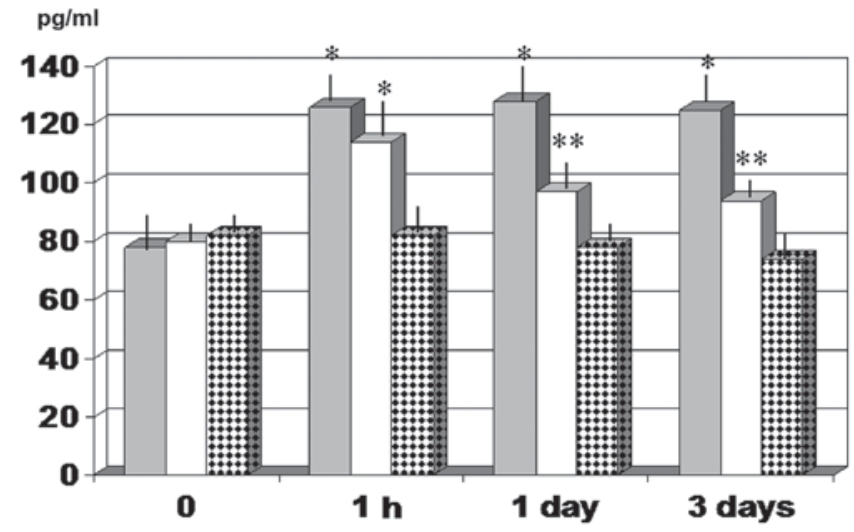

Figure 3. Interleukin-6 concentration in inflamed pharyngeal tissue in a non-infectious pharyngitis model: Effect of VBC-1814/7J. The data are expressed as the mean \pm standard error of the mean. The mean values of all the groups were compared to one-way analysis of variance followed by Bonferroni's test. ${ }^{*} \mathrm{P}<0.001$ vs. group $\mathrm{C} ;{ }^{* * *} \mathrm{P}<0.05$ vs. group A. Grey bar, untreated pharyngitis group (group A); white bar, phytocompound-treated pharyngitis group (group B); dotted bar, healthy control treated with sham pharyngeal damage (saline).
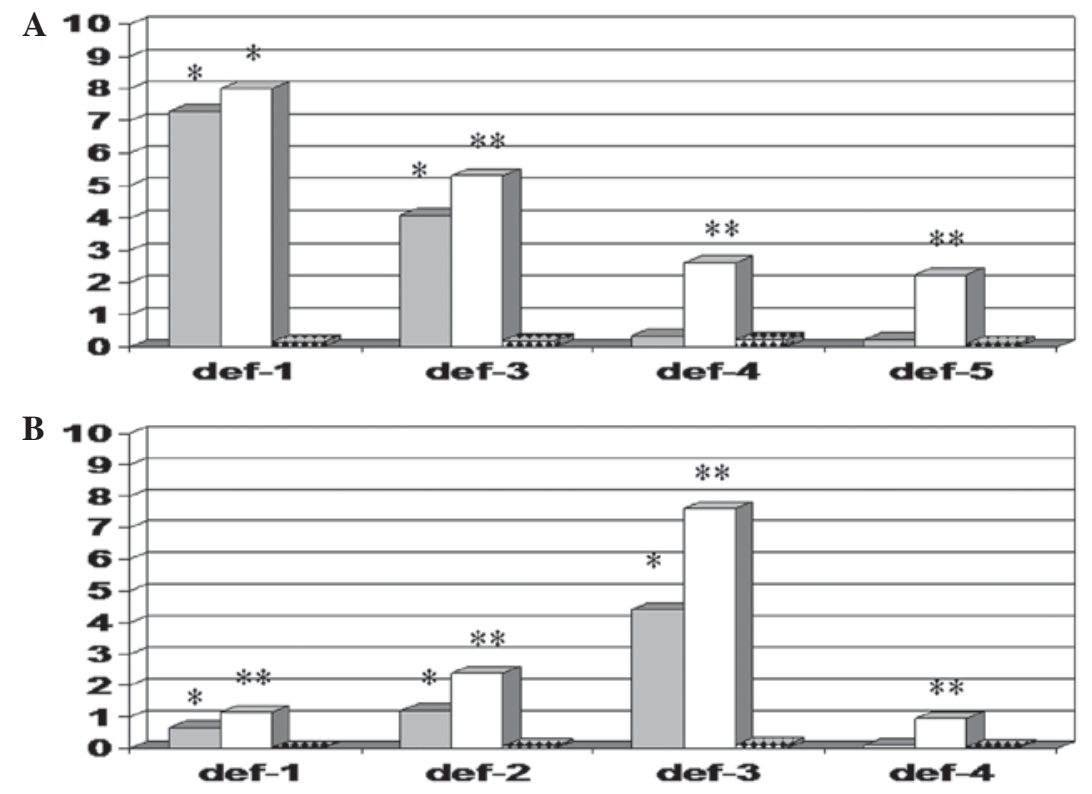

Figure 4. Assessment of defensin mRNA levels in pharyngeal tissue at the three-day observation point. (A) $\alpha$-defensins; (B) $\beta$-defensins. Values are expressed as changes in gene expression, calculated using the following formula: $\left(\mathrm{CT}_{\text {target gene }}-\mathrm{CT}_{\text {reference gene of treated rats }}\right) /\left(\mathrm{CT}_{\text {target gene }}-\mathrm{CT}_{\text {reference gene of untreated rats }}\right)$ (with CT values in arbitrary units). " $\mathrm{P}<0.001$ vs. group $\mathrm{C} ;{ }^{* *} \mathrm{P}<0.05$ vs. group A. Grey bar, untreated pharyngitis group (group A); white bar, phytocompound-treated pharyngitis group (group B); dotted bar, healthy control treated with sham pharyngeal damage (saline).

baseline and group C). Rats treated with VBC-1814/7J showed a significant increase in all defensins with the exception of $\beta$-defensins 1 and 4 as early as the one-hour time-point (data not shown; $\mathrm{P}<0.05$ vs. group $\mathrm{B}$ ). Levels of $\beta$-defensins 1 and 4 mRNA increased significantly at the third day of observation (Fig. 4; $\mathrm{P}<0.05$ vs. group $\mathrm{B}$ ).

\section{Discussion}

The physicochemical causes of sore throat have not been fully elucidated, given the complex environmental factors and unidentified overall specific receptors, although a number of putative mechanisms have been indicated. While neurogenic inflammation may be held responsible for the upper airway reaction to particulate matter and other environmental irritants through the likely interaction with transient receptor potential channels located on immune and nonimmune cells in the respiratory tract, in numerous other cases a detailed pathophysiology cannot be determined. Whatever the fine mechanisms involved, however, inflammatory infiltration phenomena with increased blood flow and vascular permeability, along with the accumulation of fluid (extravasation), represent common features. This is due to the fact that recruited monocytes/macrophages are highly sensitive to bacterial and non-bacterial stimuli and function as a principal source of proinflammatory cytokines (22). These are groups of polypeptides that play a pivotal role in orchestrating the inflammatory response, further increasing the cellular infiltration and cellular activation $(26,27)$, but also inducing defensins in respiratory tract epithelial cells (28).

In the present study it was noteworthy that a significant improvement of microscopic structure and reduced EB 
extravasation was observed, even at the one-hour evaluation point, in rats administered VBC-1814/7J. These data were in agreement with a significantly enhanced cytokine profile at the one-day observation point following the use of this poly-phytocompound, although no effect was seen immediately subsequent to the establishment of the pharyngitis model. In particular, this model showed a consistently higher IL-6 level throughout the study without the spontaneous decreasing slope pattern that occurred with TNF- $\alpha$ whereas VBC-1814/7J promoted a trend towards a constantly decreasing slope.

As expected, the pharyngitis model used in the present study triggered a significant positive defensin response but it was of interest to record that this was only partial. The defensin family of polypeptides, comprising $\alpha-, \beta$ - and $\theta$-defensins, has a specific molecular framework characterised by cysteine residues paired in disulphide bridges, and they possess relevant antibacterial and antiviral activity $(19,20)$. Of note, with the exception of two $\alpha$-defensins and one $\beta$-defensin, the immediate defensin response to the application of pyridine was not particularly marked; in such a setting VBC-1814/7J proved to beneficially modulate the overall defensin response. This is of interest when considering a recent study showing that the exposure of airway epithelial cells to T-helper-2-type cytokines, such as in allergic rhinitis, may result in a significant decrease in the capacity of defensins to exert antimicrobial activity (29).

In conclusion, although these data come from an experimental non-infectious pharyngitis model, it appears that VBC-1814/7J is safe and has the potential to be applied in clinical practice, given the inappropriate use of antibiotics (30) and the largely growing life-style situations causing sore throat (31-34).

\section{References}

1. Del Mar CB, Glasziou PP and Spinks AB: Antibiotics for sore throat. Cochrane Database Syst Rev: CD000023, 2006.

2. Wakefield M, Trotter L, Cameron M, Woodward A, Inglis G and Hill D: Association between exposure to workplace secondhand smoke and reported respiratory and sensory symptoms: cross-sectional study. J Occup Environ Med 45: 622-627, 2003.

3. Ségala C, Poizeau D, Neukirch F, Aubier M, Samson J and Gehanno P: Air pollution, passive smoking, and respiratory symptoms in adults. Arch Environ Health 59: 669-676, 2004

4. Willatt DJ: Children's sore throats related to parental smoking. Clin Otolaryngol Allied Sci 11: 317-321, 1986.

5. Wakefield M, Cameron M, Inglis G, Letcher T and Durkin S: Secondhand smoke exposure and respiratory symptoms among casino, club, and office workers in Victoria, Australia. J Occup Environ Med 47: 698-703, 2005.

6. Long J, Williford HN, Olson MS and Wolfe V: Voice problems and risk factors among aerobics instructors. J Voice 12: 197-207, 1998.

7. Williams NR: Occupational voice disorders due to workplace exposure to irritants - a review of the literature. Occup Med (Lond) 52: 99-101, 2002.

8. Bhalla RK, Taylor W, Jones AS and Roland NJ: The inflammation produced by corticosteroid inhalers in the pharynx in asthmatics. Clin Otolaryngol 33: 581-586, 2008

9. Perez-Padilla R, Schilmann A and Riojas-Rodriguez H: Respiratory health effects of indoor air pollution. Int J Tuberc Lung Dis 14: 1079-1086, 2010.

10. Liu YH, Du CL, Lin CT, Chan CC, Chen CJ and Wang JD: Increased morbidity from nasopharyngeal carcinoma and chronic pharyngitis or sinusitis among workers at a newspaper printing company. Occup Environ Med 59: 18-22, 2002.

11. de la Hoz RE, Shohet MR and Cohen JM: Occupational rhinosinusitis and upper airway disease: the world trade center experience. Curr Allergy Asthma Rep 10: 77-83, 2010.
12. Apte MG, Fisk WJ and Daisey JM: Associations between indoor $\mathrm{CO}_{2}$ concentrations and sick building syndrome symptoms in US office buildings: an analysis of the 1994-1996 BASE study data. Indoor Air 10: 246-257, 2000

13. Hahn R: Clinical evaluation of flurbiprofen alone and plus ampicillin in chronic pharyngitis in acute phase. Int J Clin Pharmacol Res 6: 81-86, 1986.

14. Cadeddu L, Piragine F, Puxeddu P, Scornavacche V and Sellari Franceschini S: Comparison of nimesulide and flurbiprofen in the treatment of non-infectious acute inflammation of the upper respiratory tract. J Int Med Res 16: 466-473, 1988.

15. Shi Y, Gu R, Liu C, Ni J and Wu T: Chinese medicinal herbs for sore throat. Cochrane Database Syst Rev: CD004877, 2007.

16. Chui HD, Kantah KM, Sweed H, He F, Ayala A, Solimene U, Hashizume H, Kobayashi K, Takadanohara H and Marotta F: Experimental evidence of effectiveness of VBC-1814/7J, a poly-phytocompound, on inflammatory and virological changes in an influenza-model. Int Med J 21: 505, 2014.

17. Badescu M, Badulescu O, Badescu L and Ciocoiu M: Effects of Sambucus nigra and Aronia melanocarpa extracts on immune system disorders within diabetes mellitus. Pharm Biol 20: 1-7, 2014.

18. Mandrone M, Lorenzi B, Maggio A, La Mantia T, Scordino M, Bruno M and Poli F: Polyphenols pattern and correlation with antioxidant activities of berries extracts from four different populations of Sicilian Sambucus nigra L. Nat Prod Res 28: 1246-1253, 2014.

19. Grishin DV and Sokolov NN: Defensins - natural peptide antibiotics of higher eukaryotes. Biomed Khim 60: 438-447, 2014 (In Russian).

20. Zhao L and Lu W: Defensins in innate immunity. Curr Opin Hematol 21: 37-42, 2014.

21. Zhang T and Liao JY: Serum levels of human $\beta$-defensins 1 and immunoglobulins $\mathrm{A}, \mathrm{G}$ and $\mathrm{M}$ in infants with recurrent pneumonia. Zhongguo Dang Dai Er Ke Za Zhi 14: 431-433, 2012 (In Chinese).

22. Prado CM, Leick-Maldonado EA, Miyamoto L, Yano LM, Kasahara DI, Martins MA and Tibério IF: Capsaicin-sensitive nerves and neurokinins modulate non-neuronal nNOS expression in lung. Respir Physiol Neurobiol 160: 37-44, 2008.

23. Frydas S, Varvara G, Murmura G, Saggini A, Caraffa A, Antinolfi $\mathrm{P}$, Tetè S, Tripodi D, Conti F, Cianchetti E, Toniato E, Rosati M, Speranza L, Pantalone A, Saggini R, Di Tommaso LM, Theoharides TC, Conti P and Pandolfi F: Impact of capsaicin on mast cell inflammation. Int J Immunopathol Pharmacol 26: 597-600, 2013.

24. Viswanatha GL, Thippeswamy AH, Rafiq M, Jagadeesh M, Baig MR, Suryakanth DA, Azeemuddin M, Patki PS and Ramakrishnan S: Novel experimental model of non-infectious pharyngitis in rats. J Pharmacol Toxicol Methods 69: 189-195, 2014.

25. Wang HL and Lai TW: Optimization of Evans blue quantitation in limited rat tissue samples. Sci Rep 4: 6588, 2014.

26. Lee LY and Yu J: Sensory nerves in lung and airways. Compr Physiol 4: 287-324, 2014

27. Sin B and Togias A: Pathophysiology of allergic and nonallergic rhinitis. Proc Am Thorac Soc 8: 106-114, 2011.

28. Verones B and Oortgiesen M: Neurogenic inflammation and particulate matter (PM) air pollutants. Neurotoxicology 22: 795-810, 2001.

29. Choi IJ, Rhee CS, Lee CH and Kim DY: Effect of allergic rhinitis on the expression of human $\beta$-defensin 2 in tonsils. Ann Allergy Asthma Immunol 110: 178-183, 2013.

30. Thomas M, Del Mar C and Glasziou P: How effective are treatments other than antibiotics for acute sore throat? Br J Gen Pract 50: 817-820, 2000

31. Van Lierde KM, Claeys S, Dhaeseleer E, Deley S, Derde K, Herregods I, Strybol I and Wuyts F: The vocal quality in female student teachers during the 3 years of study. J Voice 24: 599-605, 2010.

32. Mendell MJ, Lei-Gomez Q, Mirer AG, Seppänen O and Brunner G: Risk factors in heating, ventilating, and air-conditioning systems for occupant symptoms in US office buildings: the US EPA BASE study. Indoor Air 18: 301-316, 2008.

33. Kinshella MR, Van Dyke MV, Douglas KE and Martyny JW: Perceptions of indoor air quality associated with ventilation system types in elementary schools. Appl Occup Environ Hyg 16: 952-960, 2001.

34. Mäkinen TM, Juvonen R, Jokelainen J, Harju TH, Peitso A, Bloigu A, Silvennoinen-Kassinen S, Leinonen M and Hassi J: Cold temperature and low humidity are associated with increased occurrence of respiratory tract infections. Respir Med 103: 456-462, 2009. 